\title{
EDITORIAL: LINGUISTIC DIVERSITY AND SOCIAL INCLUSION IN AUSTRALIA
}

\begin{abstract}
Ingrid Piller Macquarie University
ingrid.piller@mq.edu.au

This editorial introduction orients the reader to current public debates and the state of research with regard to the intersection of linguistic diversity and social inclusion in contemporary Australia. These are characterised by a persistent lack of attention to the consequences of linguistic diversity for our social organisation. The editorial introduction serves to frame the five original research articles that comprise this special issue and identifies the key challenges that linguistic diversity presents for a fair and just social order. These challenges run as red threads through all the articles in this issue and include the persistent monolingual mindset which results in a pervasive language blindness and an inability to even identify language as an obstacle to inclusion. Furthermore, where language is recognised as an obstacle to inclusion this usually takes the form of assuming that an individual suffers from a lack of English language proficiency. Improving English language proficiency is then prescribed as a panacea for inclusion. However, on close examination that belief in itself can constitute a form of exclusion with detrimental effects both on language learning and equal opportunity.
\end{abstract}

KEY WORDS: discrimination, exclusion, interaction, language hierarchy, monolingual mindset

\section{INTRODUCTION}

It is the aim of this special issue to explore the intersection between linguistic diversity and social inclusion in contemporary Australia. The articles collected here are based on a selection of presentations during a workshop devoted to the same topic and conducted at Macquarie University in October 2012. ${ }^{i}$ This editorial introduction is intended to frame the issue and to provide an overview of the articles. Beginning with an orientation to linguistic diversity in Australia, I argue that there currently is a lack of public debate as to what everincreasing linguistic diversity might mean for the way we conduct our social affairs. This lack of public debate is mirrored in the field of (applied) linguistics, where the intersection between linguistic diversity and social inclusion does not at present constitute a significant research enterprise, as the next section shows. I then move on to discuss two key social inclusion challenges arising from linguistic diversity and which are explored in detail in the following articles: first, there is an urgent need to make language visible and to find better ways to speak about linguistic diversity than existing crude approaches focusing on named languages allow. Second, there is an equally urgent need to understand and raise awareness of the ways in which English language learners and users of English as an additional 
language are excluded in interaction and the consequences such exclusions have both for their language learning and their overall well-being.

\section{LINGUISTIC DIVERSITY IN AUSTRALIA}

It is to state the obvious that contemporary Australia is a highly linguistically diverse society. In each consecutive census, the percentage of Australian residents who speak only English has fallen: from $79.1 \%$ in 2001 to $77.7 \%$ in 2006 to $76.0 \%$ in 2011 (Australian Bureau of Statistics, 2012a). This means that around a quarter of the population is bi- or multilingual. Australia's linguistic diversity and the linguistic diversity of its communities and institutions are widely considered to be a cause for celebration. For instance, the subtitle of a recent newspaper article about linguistic diversity in Sydney (Ting \& Walters, 2014) boasted: 'From Afrikaans to Telugu, Hebrew to Wu, the depth and diversity of languages in Sydney rivals some of the world's largest cities'. Similarly, reports of community and institutional profiles now frequently include information on linguistic diversity within their area or organisation. The 2013 Annual Report of my institution, for instance, states: 'Macquarie University's staff body is highly diverse, comprising staff from 80 countries, who speak 66 different languages' (Macquarie University, 2014, p. 26).

However, while the fact of linguistic diversity in Australia is well-recognised, frequently enumerated, and even celebrated, there is currently a distinct absence of any public discussion of what this might mean for our social organisation. How does linguistic diversity structure contemporary Australian society? How does linguistic proficiency mediate social participation? What is the actual lived experience of linguistic diversity? Questions such as these which explore the intersection between linguistic diversity and social organisation are rarely being asked and are certainly not at the centre of any sustained public debate.

This is a remarkable state of affairs considering that public awareness of and policy responses to the social consequences of linguistic diversity arising from migration placed Australia in the avant-garde internationally in the 1970s and 1980s. At that time 'intense activity from professional and community groups' (Lo Bianco, 1987, p. 2) resulted in a bipartisan political consensus that Australia's linguistically diverse society needed a language policy to ensure equality of opportunity regardless of language background. The Australian Senate set four guiding principles to undergird the 'National Policy on Languages' (Lo Bianco, 1987). These included competence in English for all; maintenance and development of languages other than English; provision of services in languages other than English; and opportunities to learn additional languages for all. Sadly, the broad coalitions that put linguistic diversity and social inclusion at the centre of national debates have long since disappeared and, as Michael Clyne (2007) noted: 'Language and languages are not a major public issue today the way that history is. We do not have the context that generated enthusiasm and support for language in the past.' (p. 5) 
This special issue is intended as a contribution towards reviving the national conversation around linguistic diversity and social justice in a new context where, as noted above, the linguistic diversity of our society is ever more palpable.

\section{LINGUISTIC DIVERSITY AND SOCIAL INCLUSION}

Social inclusion primarily refers to the promotion of economic well-being, particularly through employment, but also includes other indices of human development such as health and education, which in turn are embedded in the wider meaning of social inclusion as a sense of community participation and belonging (see Piller, 2012; Piller \& Takahashi, 2011a for further discussion). Linguistic diversity is highly relevant to social inclusion as the languages someone speaks (or not) influence which jobs they can get, which information they can access, and who they can socialise with. However, there is currently a gap in the knowledge between the sociologies of inclusion and language.

Not only is there currently little public debate about the relationship between linguistic diversity and social inclusion, as discussed above, but the field of (applied) linguistics, too, has sidelined this topic. The question of how language serves to reproduce social inequality was a foundational concern of the modern discipline of sociolinguistics but has been neglected since the field's post-modern turn in the 1990s when 'identity' emerged as the central social category to replace 'inequality' (Collins, 2009). This situation has only recently begun to change again with publications such as Block, Gray and Holborow (2012), Duchêne, Moyer and Roberts (2013), Martín Rojo (2010), or Piller and Takahashi (2011b). Within Australian linguistics, too, there is now a re-emerging focus on the social consequences of linguistic diversity in contexts relevant for social inclusion such as education (e.g., Wigglesworth, 2013) and employment (e.g., Piller \& Lising, 2014; Piller \& Takahashi, 2013).

Broadly speaking, the situation described above for (applied) linguistics is mirrored in sociology. There, too, we find that language was central to the work of at least two of the major theorists of social reproduction, Basil Bernstein and Pierre Bourdieu. However, today, even such eminent theorists of social justice as Brian Barry (2005), by and large, ignore the linguistic dimension of social reproduction. Policy makers in social inclusion too almost consistently ignore language. In Australia's now-defunct social inclusion policy 'A Stronger, Fairer Australia - a new social inclusion strategy' from 2009 'language' hardly ranks a mention, as Musgrave and Bradshaw demonstrate.

In sum, there is an urgent need for a sustained and coherent research enterprise that puts questions of social justice at the heart of explorations of linguistic diversity and, conversely, writes language into the social inclusion agenda. This special issue is intended to contribute towards filling this gap and to build on foundational interdisciplinary work exploring the 
intersection between language and inequality in a new era of global social transformations and with specific attention to the Australian national context.

\section{MAKING LANGUAGE VISIBLE}

Australia has long been characterised by 'a monolingual mindset' (Clyne, 2005), which has resulted in monolingual institutions rendering the fact of linguistic diversity invisible and constructing it as problematic (see Ellis, Gogolin, \& Clyne, 2011 for further discussion). At first blush, the increasing frequency of public statements such as ' $x$ number of languages are spoken in our community/institution' might be considered as evidence that the force of the monolingual mindset is waning. However, such quantifications of linguistic diversity continue to obscure the fact that - socially - some languages are more equal than others and that the relationship between languages and their speakers is hierarchically structured.

The hidden hierarchical structure of linguistic diversity is best evidenced by the fact that English spoken with an accent which bears no traces of other languages - so-called 'native' English - is not typically considered a feature of linguistic diversity in Australia. The absurd term 'culturally and linguistically diverse,' or 'CALD' for short, is used to refer only to those who speak English as an additional language and/or are not of Anglo-Celtic stock. Logically, everyone is culturally and linguistically diverse, of course, and English is 'diverse' from other languages as well as characterised by internal diversity in the same way that any other language or language variety is. Therefore, discourses of linguistic diversity do not really transcend the monolingual mindset if all they do is reify linguistic difference between 'English' and 'Other'.

Not only are languages other than English less valued than English but these languages are, in turn, hierarchically structured. Prestigious foreign languages taught in school (e.g., French, German, Japanese) are followed by community languages that have some presence in the school system (e.g., Chinese, Greek, Italian). These in turn are valued more than community languages which are rarely learnt outside their communities (e.g., Dari, Dinka, Vietnamese). The bottom of the language pyramid is populated by Aboriginal languages and languages whose very language status is in doubt because they are classified as 'creoles,' 'dialects' or 'pidgins.'

In fact, the monolingual mindset results in an understanding of linguistic diversity as comprising neatly compartmentalised nameable languages that bear no traces of contact with each other. Contact varieties are a central aspect of linguistic diversity and ignoring them can have profound consequences for the educational success of children, as Dixon and Angelo demonstrate. In their analysis of the language data about Aboriginal children held by Queensland schools they find that these data are 'inaccurate, illogical and incomplete' and fail to capture students' proficiency levels in Standard Australian English and their status as 
learners (or not) of this variety. Dixon and Angelo's research serves as a stark reminder of the actual level of ignorance about linguistic diversity that can be found in Australian society and the consequences this has for the educational disadvantage of Aboriginal children.

\section{ENGLISH MARKED BY OTHER LANGUAGES AND EXCLUSION}

As explained in the previous section, linguistic diversity in Australia is reified as a hierarchy where the main boundary is between 'English' and 'Other'. It is mostly only the latter which is imagined to comprise 'diversity'. However, the social consequences of linguistic diversity are most strongly felt in English, specifically in English that is marked by the presence of other languages in the speaker's repertoire. Social exclusion based on language as documented in this volume mostly plays out on the terrain of English. This is so despite the fact that there are actually few Australian residents whose repertoire does not include English. In the 2011 census, only 513,583 residents (2.4\% of the total population or $9.8 \%$ of the people who claimed a home language other than English) stated that they spoke English 'not well or not at all' (Australian Bureau of Statistics, 2012b). Even so, if linguistic diversity is recognised as an obstacle to social inclusion, it is usually assumed that the only such linguistic obstacle that exists is low English proficiency. Consequently, there is a facile assumption that English language learning will improve social inclusion, as Musgrave and Bradshaw and Butorac show. This assumption is fallacious for a number of reasons, a topic that all the articles in this special issue engage with.

To begin with, it is another expression of the monolingual mindset that the capacity to diagnose language proficiency is not well developed in Australia and the diagnosis of 'low proficiency' English frequently rests on nothing more than the presence of a 'non-native' accent. As Dixon and Angelo demonstrate, even educators are poorly equipped to distinguish between speakers and learners of Standard Australian English. Furthermore, Butorac finds that language can become a proxy for race. The Asian participants in her study (see also Butorac, 2011) reported that they were frequently treated as deficient English speakers irrespective of their actual language proficiency simply on the basis of their physical appearance (see Piller, 2011, Chapter 9 for further discussion).

Second, improving English language proficiency is not necessarily something that can be achieved prior to and in the absence of social inclusion. As Major, Terraschke, Major, and Setijadi and Chang demonstrate, language learning and social inclusion are dialectically related. Based on migrants' self-reports about their workplace interactions, Major et al. argue that improved English proficiency is the result of a certain degree of social inclusion - here understood as a sense of belonging, connectedness, and being accepted by co-workers. Conversely, Chang's study of the feedback received by international students in higher education demonstrates that the absence of meaningful feedback bars international students 
from improving their academic writing in English and excludes them from content learning at the same time.

\section{CONCLUSION}

It is the overall aim of this special issue to put the intersection of linguistic diversity and social justice on the map, both as the central challenge for a sociolinguistics of mobility for the $21^{\text {st }}$ century and as a central policy challenge for Australia, as it is for all other internationalising and globalising societies. Bridging the gap between the sociologies of language and inclusion is essential to inform language policies that serve the common good.

The articles presented here address a number of challenges that are central to this endeavour. These include identifying and addressing a pervasive language blindness in social policy (Musgrave \& Bradshaw) and education (Dixon \& Angelo); disentangling the conflation between language and race and calling out purported diagnoses of limited English language proficiency masquerading as racial discrimination (Butorac); and exploring the intersection between exclusion and language learning in workplaces (Major et al.) and higher education (Chang).

Exploring linguistic diversity from the perspective of social inclusion also challenges us to interrogate the linguistic ideologies that inform professional linguistics and public discourse alike. These include an excessive focus on language varieties that have a name to the detriment of contact varieties that remain unnamed, invisible, and underexplored (Dixon \& Angelo); if contact varieties do come into focus they are viewed as problematic and deficient and as something speakers need to work to overcome in order to be 'included' (all contributions). The articles collected here also alert us to the fact that from the perspective of social inclusion the relative isolation of scholarship devoted to Aboriginal languages from scholarship devoted to migrant languages needs to be overcome (see Lo Bianco, 2014 for further discussion).

Finally, the articles assembled here are characterised by a certain negativity documenting as they do pervasive language blindness and the pervasive exclusion of speakers constructed as 'the linguistically diverse Other'. However, it is equally important to shine the research spotlight on positive instances of inclusion. And all articles do indeed also offer positive, albeit isolated, examples of instances of inclusion in friendship groups (Butorac), workplace interactions (Major et al.), or academic learning experiences (Chang), alerting us, yet again, to the fact that social inclusion is a complex, multi-layered endeavour playing out in the perpetual dialectic of social structure and individual agency. 


\section{REFERENCES}

Australian Bureau of Statistics. (2012a). 2011 Census of population and housing: Time series profile, Australia. Canberra: Australian Bureau of Statistics.

Australian Bureau of Statistics. (2012b). 2011 Census of population and housing: Basic community profile, Australia. Canberra: Australian Bureau of Statistics.

Barry, B. (2005). Why social justice matters. Oxford: Polity.

Block, D., Gray, J., \& Holborow, M. (2012). Neoliberalism and applied linguistics. London: Routledge.

Butorac, D. (2011). Imagined identity, remembered self: Settlement language learning and the negotiation of gendered subjectivity (Unpublished doctoral dissertation). Macquarie University, Sydney, New South Wales, Australia. Retrieved from http://www.languageonthemove.com/wpcontent/uploads/2012/03/DButorac_PhD.pdf.

Clyne, M. (2005). Australia's language potential. Sydney: UNSW Press.

Clyne, M. (2007). Are we making a difference? On the social responsibility and impact of the linguist/applied linguist in Australia. Australian Review of Applied Linguistics, 30(1-14), 03.103.14 .

Collins, J. (2009). Social reproduction in classrooms and schools. Annual Review of Anthropology, 38(1), 33-48. doi: 10.1146/annurev.anthro.37.081407.085242

Duchêne, A., Moyer, M., \& Roberts, C. (Eds.). (2013). Language, migration and social inequalities: A critical sociolinguistic perspective on institutions and work. Bristol: Multilingual Matters.

Ellis, E. M., Gogolin, I., \& Clyne, M. (2011). The Janus face of monolingualism: A comparison of German and Australian language education policies. Current Issues in Language Planning, 11(4), 439-460.

Lo Bianco, J. (1987). National policy on languages. Canberra: Australian Government Publishing Service.

Lo Bianco, J. (2014). Domesticating the foreign: Globalization's effects on the place/s of languages. The Modern Language Journal, 98(1), 312-325. doi: 10.1111/j.1540-4781.2014.12063.x

Macquarie University. (2014). Macquarie University annual report 2013. North Ryde: Macquarie University.

Martín Rojo, L. (2010). Constructing inequality in multilingual classrooms. Berlin: Mouton de Gruyter.

Piller, I. (2011). Intercultural communication: A critical introduction. Edinburgh: Edinburgh University Press.

Piller, I. (2012). Multilingualism and social exclusion. In M. Martin-Jones, A. Blackledge, \& A. Creese (Eds.), The Routledge handbook of multilingualism (pp. 281-296). London: Routledge.

Piller, I., \& Lising, L. (2014). Language, employment and settlement: Temporary meat workers in Australia. Multilingua, 33(1/2), 35-59.

Piller, I., \& Takahashi, K. (2011a). Linguistic diversity and social inclusion. International Journal of Bilingual Education and Bilingualism, 14(4), 371-381.

Piller, I., \& Takahashi, K. (Eds.). (2011b). Linguistic diversity and social inclusion [Special Issue]. International Journal of Bilingual Education and Bilingualism, 14(4), 371-381. 
Piller, I., \& Takahashi, K. (2013). Language work aboard the low-cost airline. In A. Duchêne, M. Moyer, \& C. Roberts (Eds.), Language, migration and social inequalities: A critical sociolinguistic perspective on institutions and work (pp. 95-117). Clevedon: Multilingual Matters.

Ting, I., \& Walters, C. (Eds.). (2014, July 11). Sydney's melting pot of language. Sydney Morning Herald. Retrieved from http://www.smh.com.au/data-point/sydney-languages/index.html.

Wigglesworth, G. (Ed.). (2013). Teaching Creole-speaking children: Issues, concerns and resolutions for the classroom [Special Issue]. Australian Review of Applied Linguistics, 36(3), 232-233.

\section{ENDNOTES}

i See http://www.languageonthemove.com/linguistic-diversity-social-inclusion for further information, including program, abstracts, video recordings, and commentaries. The workshop organisers gratefully acknowledge funding received from Macquarie University's Faculty of Human Sciences to run the workshop as part of the Human Sciences Perspectives series. As the guest editor of this special issue, I also gratefully acknowledge the research assistance provided by Hanna Torsh and Shiva Motaghi-Tabari, and the editorial support provided by Angela Turzynski-Azimi. 